\title{
Distribusi Parameter Oseanografi dengan Hasil Tangkapan Ikan Pelagis Kecil untuk Pemetaan Distribusi Daerah Potensial Penangkapan di Perairan Teluk Weda
}

\author{
Abdul Haris B ${ }^{1}$, Umar Tangke ${ }^{2 凶}$, dan Syahnul Sardi Titaheluw ${ }^{2}$ \\ 1 Mahasiswa Program Studi Teknologi Hasil Perikanan, Fakultas Pertanian dan Perikanan, Universitas Muhammadiyah \\ Maluku Utara. Ternate, Indonesia. \\ 2 Staf Pengajar Program Studi Teknologi Hasil Perikanan, Fakultas Pertanian dan Perikanan, Universitas Muhammadiyah \\ Maluku Utara. Ternate, Indonesia. \\ Email : umbakhaka@gmail.com
}

${ }^{\square}$ Korespondensi : Umar Tangke, Universitas Muhammadiyah Maluku Utara. Ternate, Indonesia, Email : umbakhaka@gmail.com

\begin{abstract}
ABSTRAK
Penelitian ini bertujuan untuk menganalisis variasi spasial dan temporal konsentrasi klorofil-a dan sebaran suhu permukaan laut di perairan Teluk weda kabupaten Halmahera Tengah dan faktor-faktor yang mempengaruhinya, dan menganalisis hubungan konsentrasi klorofil-a dan suhu permukaan laut dengan hasil tangkapan ikan pelagis di perairan Teluk Weda Kabupaten Halmahera Tengah. Penelitian ini merupakan jenis penelitian empirik dengan metode eksperimental fishing, yaitu kegiatan penelitian yang dilakukan bersamaan dengan kegiatan penangkapan oleh nelayan. Proses pengambilan data primer berupa data posisi tangkap, jumlah hasil tangkapan, suhu permukaan laut dan klorofil-a dilakukan dilapangan pada saat operasi penangkapan berlangsung. Hasil penelitian di perairan teluk weda kondisi klorofil-a pada perairan teluk weda cukup fluktuatif pada bulan September 2020 sampai Februari 2021 dengan nilai rata-rata adalah $1.0 \mathrm{mg} / \mathrm{m}^{3}$, dan nilai terendah adalah $0.4 \mathrm{mg} / \mathrm{m}^{3}$ pada bulam Februari 2021 dan nilai tertinggi $1.8 \mathrm{mg} / \mathrm{m}^{3}$ pada bulan Oktober 2020. Jenis tangkapan ikan pelagis kecil yamg merupakan hasil tangkapan kapal KM. Panzer 01 diperairan teluk weda adalah terdiri dari ikan layang (Decapterus sp), tongkol (Euthynnus affinis) kembung (Rastreliger $s p$ ), dan selar (Selaroides $s p$ ). Komuditas tangkapan utama yang didaratkan adalah ikan layang yang merupakan spesies dominan dengan presentase mencapai $80-90 \%$ dari total hasil tangkapan.
\end{abstract}

Keyword: Ikan pelagis Kecil, Klorofil-a, Teluk Weda

\section{PENDAHULUAN}

Perairan Halmahera Tengah terletak di antara $0^{0} 45$ Lintang Utara - $0^{0} 45$ Lintang Selatan dan $127^{4} 45-129026$ Bujur timur. Luas wilaya Kabupaten Halmahera tengah tercatat 8.381,84 km² (daratan 2.276,83 $\mathrm{km}^{2}$, lautan 6.104,65 $\mathrm{km}^{2}$ ). Sekitar 73\% Wilaya Halmahera tengah merupakan lautan. Sedangkan $27 \%$ lainnya merupakan daratan, sehingga kaya akan sumberdaya ikan terutama ikan pelagis kecil. Ikan pelagis kecil adalah jenis ikan yang hidup bergerombol didekat permukaan perairan diantaranya jenis ikan layang, ikan tongkol, ikan selar, kembung dan ikan teri. Potensi sumberdaya ikan pelagis kecil di kabupaten Halmahera Tengah mencapai 7.671,46/ ton per tahun yang terdiri dari dengan tingkat eksploitasi yang diijinkan adalah sebesar 19.376,47 ton per tahun dari potensi lestari (MSY). Sampai saat ini tingkat pemanfaatan sumberdaya ikan pelagis kecil baru mancapai 4.632 ton per tahun atau sekitar 20\% dan sisanya 30. 567 ton (60\%) terbuang secara percuma (DKP Kabupaten Halteng, 2020).

Upaya untuk mengeksploitasi sumberdaya perikanan pelagis kecil secara optimal telah dilakukan dengan barbagai cara diantaranya penambahan jumlah armada dan alat bantu penangkapan, tetapi hal ini tidak memberikan hasil yang maksimal karena ketidakpastian daerah penangkapan karena dalam mementukan daerah penangkapan nelayan selalu berdasarkan pada skill dan pengalaman, sehingga umumnya nelayan berangkat ke laut bukan untuk menangkap tetapi 
mencari daerah penangkapan dan hal ini juga berpengaruh terhadap efisiensi dan efektivitas biaya operasioanl penangkapan.

Kegiatan penangkapan ikan akan lebih efektif dan efisien jika daerah penangkapan ikan dapat diduga terlebih dahulu sebelum nelayan melaut. Salah satu cara untuk mengetahui daerah potensial penangkapan ikan adalah dengan memanfaatkan system informasi Geografis (SIG) dan kajian daerah penangkapan hubungannya dengan parameter oseanografi secara berkelanjutan (Mardhatillah et al., 2016). Secara alami, ikan akan memilih habitat yang sesuai untuk kelangsungan hidupnya, dimana habitat tersebut sangat dipengaruhi oleh kondisi parameter oseanografi perairan diantaranya suhu permukaan laut, klorofil-a dan salinitas.

Kesesuaian lingkungan perairan yakni parameter oseanografi mempengaruhi keberadaan sumberdaya ikan dimana suhu dan salinitas berpengaruh terhadap proses metabolisme tubuh, distirbusi, berkembangbiak dan tumbuh, sedangkan klorofil-a lebih mempengaruhi produktivitas perairan yang diukur dengan banyaknya kandungan fitoplankton (Akhlak et al., 2015). Berdasarkan masalah diatas maka perlu dikaji analisis parameter oseanografi khususnya suhu permukaan laut, salinitas dan klorofil-a untuk memetakan potensial penangkapan ikan pelagis kecil di perairan teluk weda Kabupaten Halmahera Tengah dengan memanfaatkan system informasi geografis (SIG).

Penelitian ini bertujuan untuk menganalisis variasi spasial dan temporal konsentrasi klorofil-a dan sebaran suhu permukaan laut di perairan Teluk weda kabupaten Halmahera Tengah dan faktorfaktor yang mempengaruhinya, dan menganalisis hubungan konsentrasi klorofil-a dan suhu permukaan laut dengan hasil tangkapan ikan pelagis di perairan Teluk Weda Kabupaten Halmahera Tengah. Manfaat dari penelitian ini adalah sebagai bahan informasi bagi nelayan dan pihak pemerintah khususnya Dinas Kelautan dan Perikanan Kabupaten Halmahera Tengah dalam pengelolaan perikanan pelagis kecil agar lebih efektif dan efisien dalam upaya meningkatkan produksi ikan pelagis kecil sampai mancapai $80 \%$ dari MSY.

\section{METODE PENELITIAN}

\subsection{Waktu dan Tempat}

Penelitian ini dilaksanakan selama satu bulan bertempat Kecamatan Weda, Kabupaten Halmahera Tengah. Alat dan bahan yang digunakan dalam penelitian ini adalah timbangan digital, GPS, thermometer, TDS, 1 unit computer, alat tulis menulis, kapal purse seine, alat tangkap purse seine dan kamera digital. Sedangkan bahan yang digunkan adalah ikan pelagis. Penelitian ini merupakan jenis penelitian empirik dengan metode eksperimental fishing, yaitu kegiatan penelitian yang dilakukan bersamaan dengan kegiatan penangkapan oleh nelayan. Proses pengambilan data primer berupa data posisi tangkap, jumlah hasil tangkapan, suhu permukaan laut dan klorofil-a dilakukan dilapangan pada saat operasi penangkapan berlangsung.

Data hasil penelitian selanjutnya di analisis dengan menggunakan analisis regresi non linier, korelasi dan analisis CPU untuk melihat hubungan dari dua variabel yakni hasil tangkapan dan parameter oseanografi dan dilanjutkan dengan analisis selanjutnya adalah analisis sistem informasi Geografis (SIG) untuk memetakan distribusi parameter oseanografi dan daerah potensial penangkapan ikan di Periaran teluk weda kabupaten Halmahera Tengah..

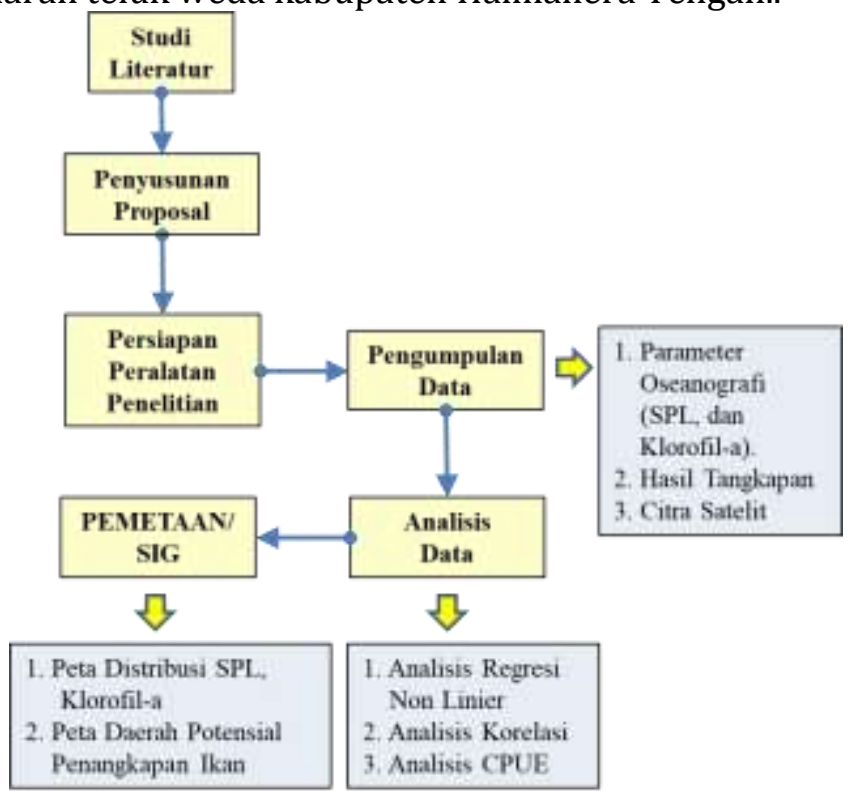

Gambar 1. Diagram Alir Proses Penelitian 
Data dalam penelitian ini terdiri dari primer dan sekunder, dimana proses pengambilan data primer adalah sebagai berikut : 1) data hasil tangkapan ikan di timbang dengan timbangan digital saat pendaratan di fishing base; 2) data suhu permukaan laut diukur dengan menggunakan thermometer digital; 3) data salinitas diukur dengan menggunkan salinometer; 4) data klorofil-a di ukur dengan TDS. Data sekunder berupa citra satelit didownload dari website https://oceancolor.gsfc.nasa.gov/l3/.

Pengolahan data SPL dan klorofil-a menggunakan perangkat lunak SeaDas 4.7 dengan sistem operasi Windows 10, kemudian ditampilkan kembali dalam bentuk grafik time series dan dalam bentuk gambar sebaran spasial. untuk dianalisis secara deskriptif. Selanjutnya produktivitas alat tangkap di analisis dengan melihat hubungan antar hasil tangkapan (catch) dengan upaya penangkapan (effort), yang disebut Catch Per Unit Effort (CPUE), dengan rumus :

$C P U E=\frac{C_{i}}{E_{i}}$

Dimana :

CPUE = Hasil per upaya tangkap yang telah distandarisasi bulan ke $\mathrm{i}$

$\mathrm{Ci} \quad=$ Hasil tangkapan pada bulan ke $\mathrm{i}$

$\mathrm{Ei} \quad=$ Upaya penangkapan pada bulan ke $\mathrm{i}$

Untuk mengkaji hubungan antara parameter oseanografi khususnya suhu permukaan laut dan konsentrasi klorofil-a dengan hasil tangkapan ikan pelagis kecil, maka kedau variabel tersebut di analisis dengan menggunakan rumus regresi eksponensial dengan model matematika adalah :

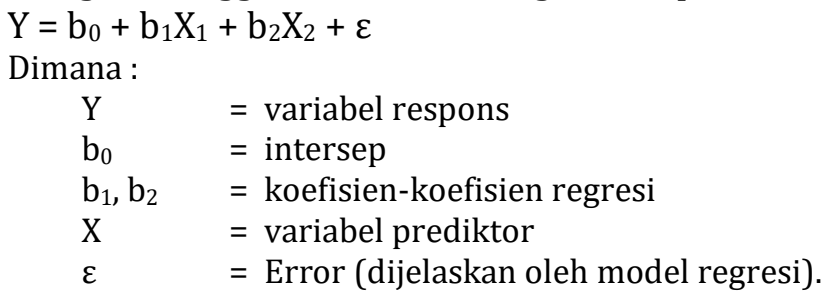

\section{HASIL DAN PEMBAHASAN}

\subsection{Distribusi Spasial dan Temporal SPL}

Informasi suhu permukaan laut merupakan parameter kualitas perairan yang paling penting di lautan yang saat ini pemantauannya dapat dilakukan secra berkala dengan memanfaatkan teknologi penginderaan jauh. Suhu Permukaan Laut memiliki peran penting bagi organisme laut karena, dapat mempengaruhi dinamika atau pergerakan air laut secara horizontal maupun vertikal (Azizah dan Wibisana 2020). Menurut Yuniarti, et al., (2013) suhu dapat mempengaruhi sistem metabolisme, perkembangbiakan maupun habitat dari organisme di laut.

Hasil ekstrkasi citra AQUA MODIS untuk daerah perairan Teluk Weda, didapat fluktuasi dan distribusi suhu permukaan laut dari bulan Septembr 2020 sampai Februari 2021, dapat dilihat pada Gambar 2 dan Gambar 3. Gambar 2 dapat dilihat bahwa fluktuasi nilai suhu permukaan laut di perairan Teluk Weda cukup fluktuatif dengan kisaran suhu rata-rata $27.4{ }^{\circ} \mathrm{C}$ sampai $30.0{ }^{\circ} \mathrm{C}$, dimana kondisi suhu permukaan tersebut masih dalam kondisi kisaran suhu yang baik bagi kehidupan organisme perairan karena masih berada dalam ranges suhu permukaan laut $18-30^{\circ} \mathrm{C}$ (Nontji, 2002).

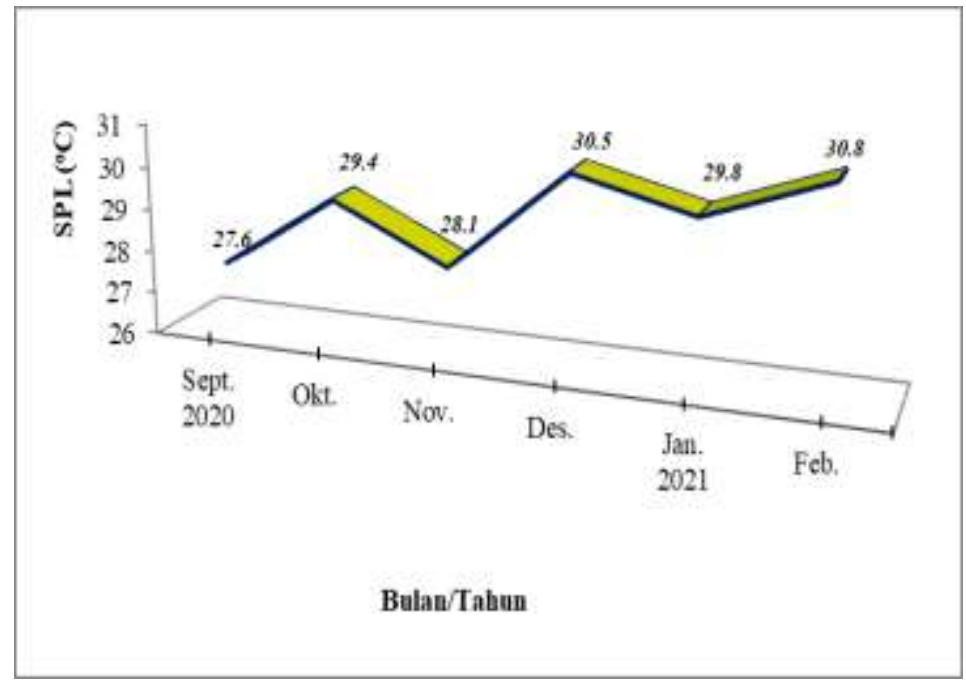

Gambar 2. Fluktuasi Rata-Rata SPL Bulan September 2020 Sampai Februari 2021 
Gambar 3, menggambarkan kondisi distribusi suhu permukaan laut pada lokasi perairan Teluk Weda, dimana terlihat bahwa pada bulan September 2020, kondisi suhu permukaan laut pada lokasi penelitian berada pada kisaran rata-rata $27.4{ }^{\circ} \mathrm{C}$ yang kemudian naik menjadi $29.4{ }^{\circ} \mathrm{C}$ pada bulan Oktober 2020. Pada bulan November 2020 suhu permukaan laut pada lokasi penelitian kembali turun menjadi $28.1^{\circ} \mathrm{C}$, yang kemudian berfluktuasi pada bulan Desember 2020, Januari dan Februari 2021 dengan nilai rata-rata masing-masing bulan adalah $30.5^{\circ} \mathrm{C}, 29.8^{\circ} \mathrm{C}$ dan $30.8^{\circ} \mathrm{C}$.

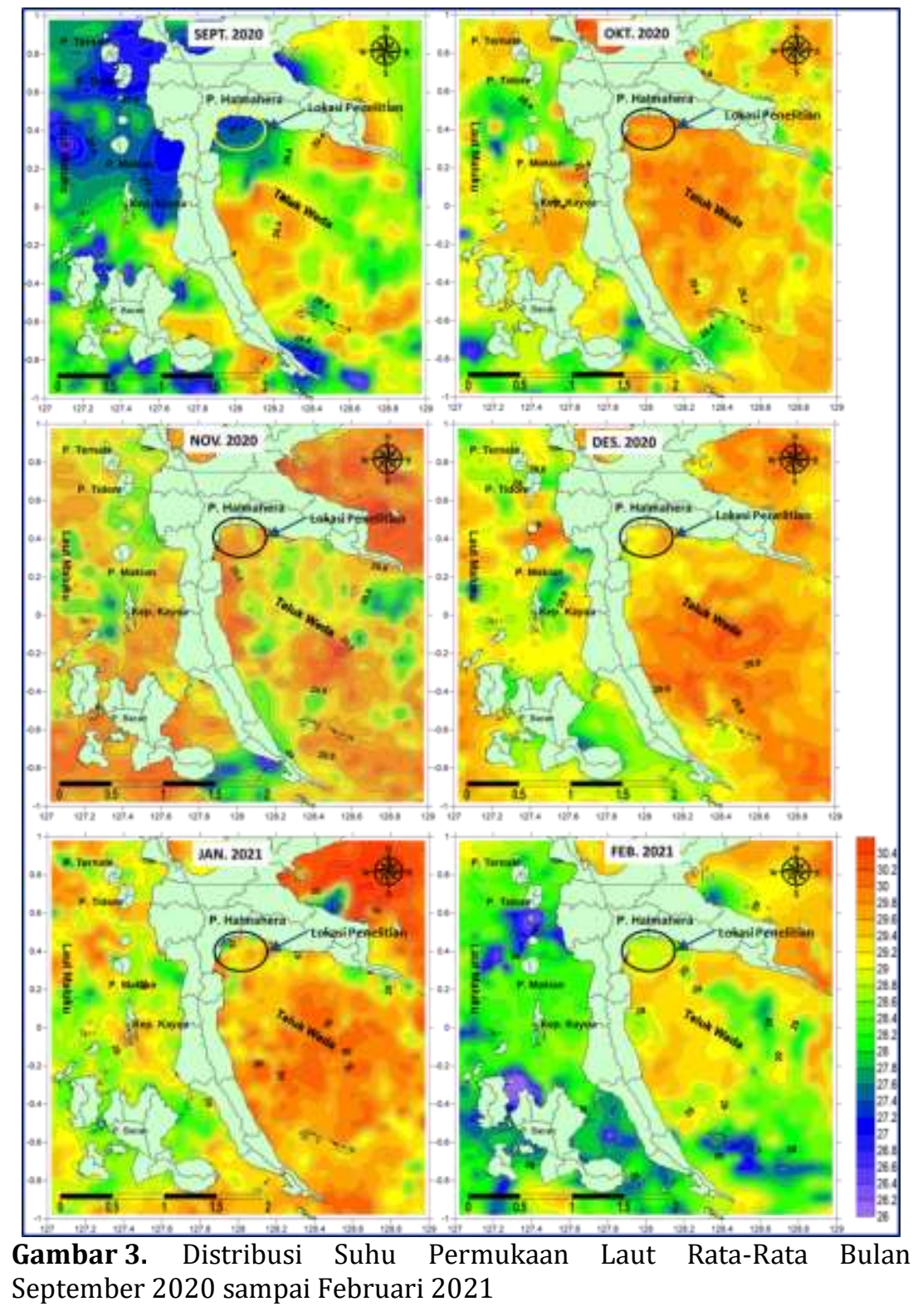

Suhu permukaan laut merupakan salah satu parameter oseanografi yang berfluktuatif setiap waktu, suhu permukaan laut dapat diukur secara langsung dengan cara pengukuran insitu maupun oleh sensor satelit yang bekerja pada spektrum infra merah termal (Wicaksono, et al., 2010). Fluktuasi suhu permukaan laut selama bulan September 2020 sampai Februari 2021 diduga disebabkan oleh kondisi meterologi dan angin monsoon yang bertiup, hal ini sesuai dengan pendapat Arief, et al., (2015), bahwa suhu permukaan laut umumnya di pengaruhi oleh kondisi panas matahari, arus permukaan, keadaan awan, upwelling, divergensi dan konvergensi terutama pada daerah muara dan sepanjang garis pantai.

Hamuna et al., (2015), suhu perairan mengalami variasi dari secara periodik sesuai dengan kondisi alam yang mempengaruhi perairan tersebut. Salah satu faktor yang mempengaruhi distribusi suhu permukaan laut di perairan Indonesia adalah angin Muson (Putra, et al., 2019; Kasim, 2010). Selain angin muson, penyebab lain terjadinya variasi suhu di perairan Indonesia yaitu El NiñoSouthern Oscillation (ENSO) dan Indian Ocean Dipole Mode (IOD) (Putra et al., 2019; Putra and Tanaka, 2013a; Sprintall et al., 2014; Sukresno, 2010; Susanto, et al., 2002). 


\subsection{Distribusi Spasial dan Temporal Klorofil-a}

Klorofil-a digunakan sebagai ukuran banyaknya fitoplankton pada suatu perairan tertentu dan dapat digunakan sebagai petunjuk produktivitas perairan (Saing et al., 2018). Menurut Simbolon \& Girsang (2009), Klorofil-a merupakan pigmen yang umumnya terdapat dalam fitoplankton dan berperan dalam fotosintesis, sehingga fitoplankton sangat berperan penting sebagai produsen primer dalam rantai makanan di perairan yang selanjutnya mempengaruhi kesuburan perairan dan keberadaan ikan termasuk ikan pelagis.

Kondisi klorofila-a di perairan Teluk Weda dapat dilihat pada Gambar 4 dan Gambar 5, dimana pada Gambar 4 terlihat bahwa kondisi klorofil-a cukup fluktuatif pada bulan September 2020 sampai Februari 2021 dengan nilai rata-rata adalah $1.0 \mathrm{mg} / \mathrm{m}^{3}$, dan nilai terendah adalah $0.4 \mathrm{mg} / \mathrm{m}^{3}$ pada bulam Februari 2021 dan nilai tertinggi $1.8 \mathrm{mg} / \mathrm{m}^{3}$ pada bulan Oktober 2020 .

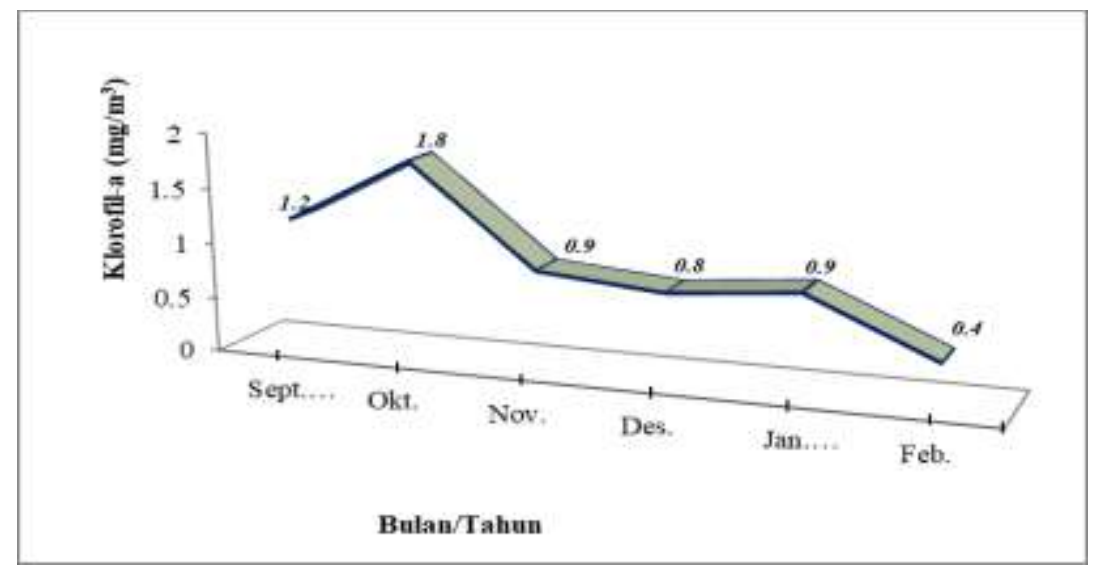

Gambar 4. Fluktuasi Rata-Rata Klorofil-a Bulan September 2020 sampai Februari 2021

Gambar 5, meunjukan distribusi spasial dan temporal klorofil-a di daerah Teluk Weda dimana terlihat bahwa pada lokasi penelitian, kondisi konsentrasi klorofil-a cukup tinggi pada bulan Oktober 2020 dan rendah pada bulan Februari 2021. Konsentrasi klorofil-a pada lokasi penenlitian yang merupakan daerah disekitar pesisir pantai terlihat berfluktuasi dari bulan Spetember 2020 sampai Februari 2021, hal ini diduga terjadi karena kondisi meteorologi yakni sinar matahari dan curah hujan sehingga menyebabkan terjadinya proses fotosintesis yang terjadi pada daerah terumbu karang serta banyaknya zat hara yang masuk ke perairan laut melalui aliran sungai.

\subsection{Tangkapan per Unit Upaya (CPUE)}

Jenis hasil tangkapan ikan pelagis kecil yang merupakan hasil tangkapan kapal KM. Panzer 01 di perairan Teluk Weda adalah terdiri dari ikan layang (Decapterus $s p$ ), tongkol (Euthynnus affinis), kembung (Rastreliger $s p$ ), dan selar (Selaroides $s p$ ). Komuditas tangkapan utama yang didaratkan adalah ikan laying yang merupakan spesies dominan dengan persentase mencapai $80-90 \%$ dari total hasil tangkapan. Nilai CPUE tangkapan ikan pelagis kecil di perairan Teluk Weda dapat dilihat pada Gambar 6.

Gambar 6, dalam rentang waktu 6 bulan terlihat nilai CPUE hasil tangkapan menunjukan trend yang menurun, dimana kondisi CPUE tertingi terdapat pada bulan November 2020 hal ini terjadia karena pada bulan November biasanya merupakan musim puncak penangkapan ikan tertutama ikan pelagis. Selanjutnya terkihat bahwa CPUE terendah adalah pada bulan Februari 2021 dimana bulan ini merupakan bulan peralihan dari musim ke barat musim timur atau lebih dikenal dengan musim peralihan I, diman kondisi perairan pada musim peralihan ini cukup bergelombanng sehingga jumlah hasil tangkapan berkuranng seiring dengan berkurangnya trip penangkapan.

\subsection{Hubungan Parameter Oseanografi dengan Hasil Tangkapan}

Ikan pelagis kecil merupakan jenis ikan ekonomis penting yang hidup bergerombol di daerah dekat permukaan perairan, dimana keberadaan ikan terutama ikan pelagis kecil di lingkungan perairan sangat dipengaruhi oleh kondisi perairan, sehingga dewasa ini pemanfaatan kondisi parameter oseanografi perairan yang di kombinasikan dengan analisis Sistem Informasi Geografis (SIG) telah menjadi trend dalam menduga dan memprediksi daerah potensial penangkapan ikan dalam bentuk peta yang di informasikan kepada nelayan sehingga operasi penangkapan oleh nelayan 
dapat berjalan efektif dan efisien. Parameter oseanografi perairan yang umumnya berperan dalam proses dan aktifitas hidup ikan diantaranya suhu permukaan laut dan klorofil-a.

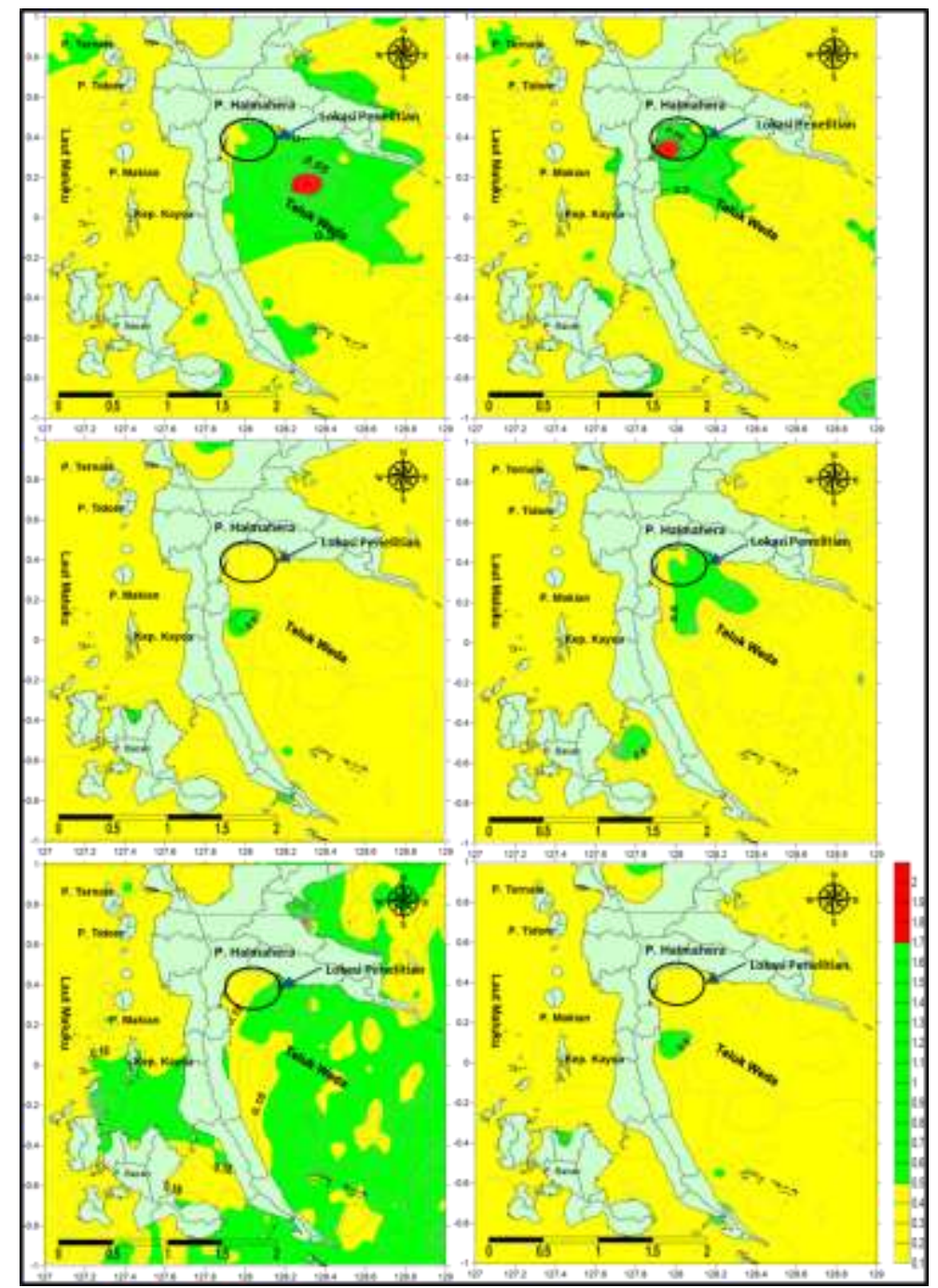

Gambar 5. Distribusi Klorofil-a Rata-Rata Bulan September 2020 sampai Februari 2021

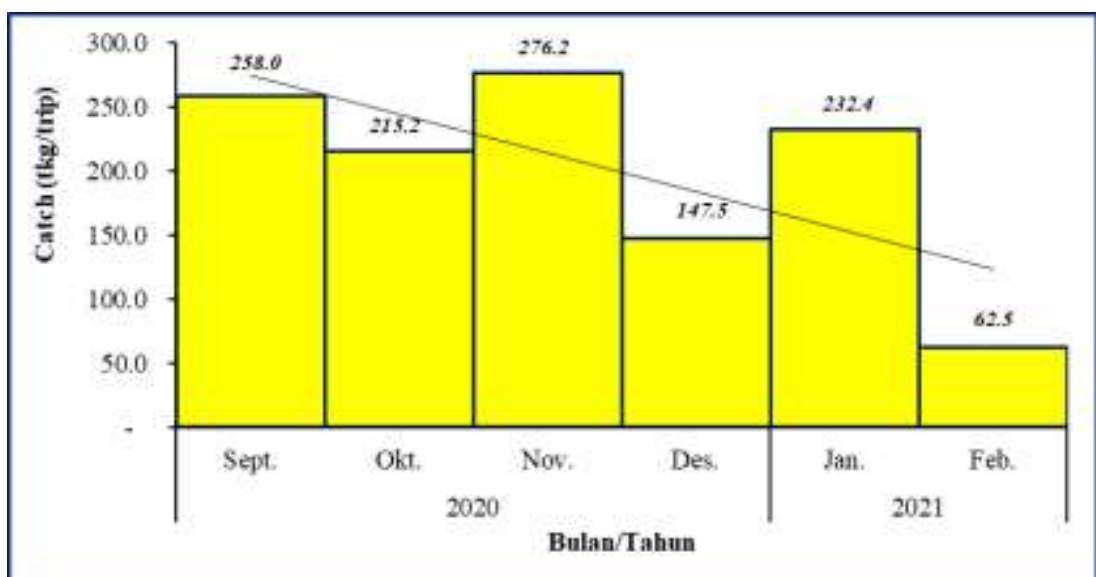

Gambar 6. Catch Per Unit Effort (CPUE) Ikan Ppelagis Kecil Bulan September 2020 sampai Februari 2021

\subsubsection{Hubungan SPL dengan Hasil Tangkapan}

Pengaruh SPL terhadap nilai CPUE hasil tangkapan ikan pelagis berbeda-beda antara satu ikan dengan ikan yang lainnya. Pada Gambar 9 terlihat bahwa kondisi suhu permukaan laut berada pada kisaran $27.6-30.8{ }^{\circ} \mathrm{C}$, dan kondisi ini suhu permukaan tersebut masih dalam kondisi kisaran suhu yang baik bagi kehidupan organisme perairan karena masih berada dalam rangex suhu permukaan laut $18-30{ }^{\circ} \mathrm{C}$ (Nontji, 2002). Suhu permukaan laut yang fluktuatif dan cenderung cenderung naik 
mulai dari bulan September 2020 sampai Februari 2021 menyebabkan terjadinya fluktuasi hasil tangkapan ikan pelagis kecil, dimana ada kecenderungan naiknya suhu permukaan laut berdampak pada menurunnya hasil tangkapan ikan pelagis kecil.

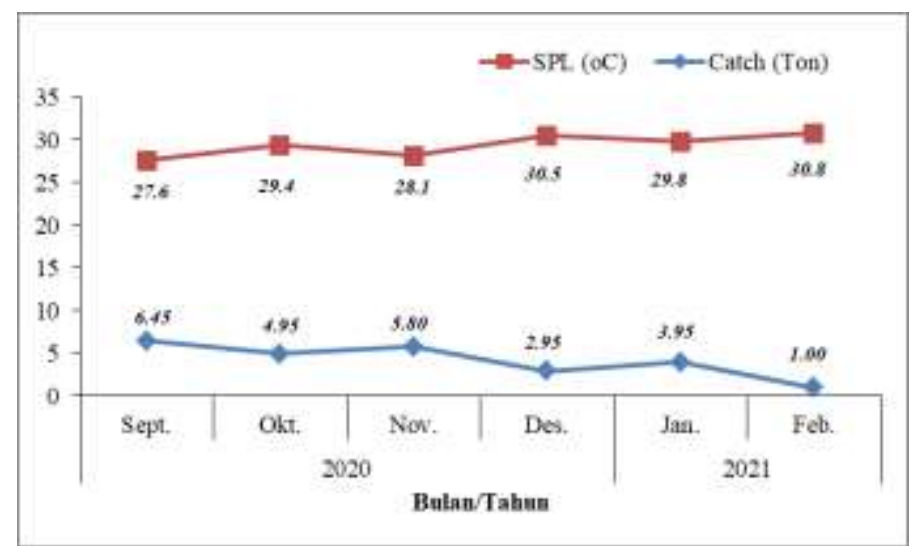

Gambar 7. Fluktuasi Rata-Rata SPL Bulanan dengan Hasil Tangkapan Ikan Pelagis Kecil di Perairan Teluk Weda Halmahera Tangah

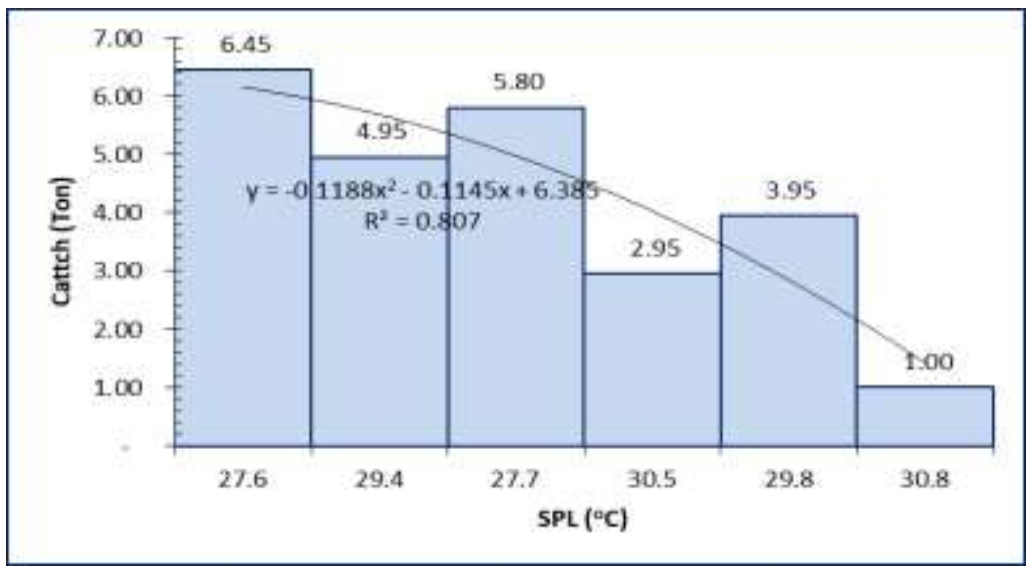

Gambar 8. Hubungan SPL dan Hasil Tangkapan Ikan Pelagis Kecil di Perairan Teluk Weda Halmahera Tangah

Gambar 8, merupakan hasil analisis hubungan antara suhu permukaan laut dengan hasil tangkapan ikan pelagis kecil secara individual menggunakan regresi polynomial, dimana terlihat bahwa suhu permukaan laut di perairan Teluk Weda memiliki hubungan yang erat dengan hasil tangkapan ikan pelagis kecil dengan nilai koefisien korelasi (r) sebesar 0.99 dan koefisien deteminasi $\left(\mathrm{r}^{2}\right)$ sebesar 0.807 . Selain itu pada grafik tersebut terlihat bahwa terjadi penurunan hasil tangkapan ikan pelagis kecil seiring dengan meningkatnya suhu permukaan laut dan kondisi tangkapan terbaik pada kisaran suhu permukaan laut antara $27.6-29.8^{\circ} \mathrm{C}$.

Fluktuasi suhu menjadi faktor penting yang merangsang dan menentukan pengkonsentrasian dan pengelompokkan ikan, dimana tinggi rendahnya suhu turut mempengaruhi produktivitas hasil tangkapan, karena setiap jenis ikan memiliki kisaran suhu tertentu untuk kelangsungan hidupnya (Zulkhasyni, 2015). Hasil penelitian Kuswanto et al (2017), suhu permukaan laut di perairan Teluk Lampung memberikan pengaruh yang nyata terhadap jenis ikan pelgis kecil khususnya ikan tongkol, hal yang sama juga didapat oleh Putra et al. (2017), dimana didapat bahwa naiknya suhu permukaan laut (SPL) diiringi dengan naiknnya CPUE ikan tongkol di perairan Laut Jawa. Bafagih et al (2017), menemukan bahwa distribusi ikan pelagis kecil, khusunya ikan julung dipengaruhi oleh suhu permukaan laut dengan nilai koefisien korelasi (r2) 0.6255, dengan suhu optimum berada pada kisaran 26.0-29.9 oC, dan hasil penelitian Akhlak et al. (2015), adanya korelasi positif antara SPL dengan hasil tangkapan ikan pelagis kecil oleh kapal purse seine yang didaratkan di TPI Bajomulyo Juwana, Pati.

\subsubsection{Hubungan Konsentrasi Klorofil-a dengan Hasil Tangkapan}

Kandungan klorofil-a pada suatu perairan sangat erat kaitannya dengan rantai makanan. Kandungan klorofil-a yang tinggi pada perairan akan meningkatkan produktifitas plankton terutama zoo plankton, sehingga tercipta suatu rantai makanan yang menunjang produktifitas ikan di perairan. 
Ikan layang banyar merupakan jenis ikan pelagis yang keberadaanya tidak secara langsung dipengaruhi oleh klorofil-a (Putra, et al., 2012).

Secara deskriptif terlihat pada Gambar 9 Pada bulan September 2020 nilai klorofil-a mencapai $1.2 \mathrm{mg} / \mathrm{m}^{3}$ dan berfluktuatif pada bulan-bulan selanjutnya dan embalit urun mencapai nilai terendah pad bulan februari 2021 sebesar $0.4 \mathrm{mg} / \mathrm{m}^{3}$. Jenis ikan pelagis kecil pada perairan Teluk Weda menunjukkan kecenderungan naiknya nilai CPUE saat konsentrasi klorofil-a tinggi dan nilai CPUE yang turun seiring dengan menurunnya kandungan konsentrasi klorofil-a di perairan tersebut.

Pada Gambar 10, dengan menggunakan analisis regresi polynomial, terlihat bahwa konsentrasi klorofil-a sangat erat hubungannya dengan hasil tangkapn ikan pelagis kecil dengan nilai koefisien korelasi (r) 0.99 dan nilia koefisien determinasi ( $r^{2}$ ) 0.807. Pada Gambar 11 terlihat juga bahwa naiknya konsentrasi klorofila-a mengindikasikan kenaikan pada nilai CPUE ikan pelagis kecil di peraian Teluk Weda.

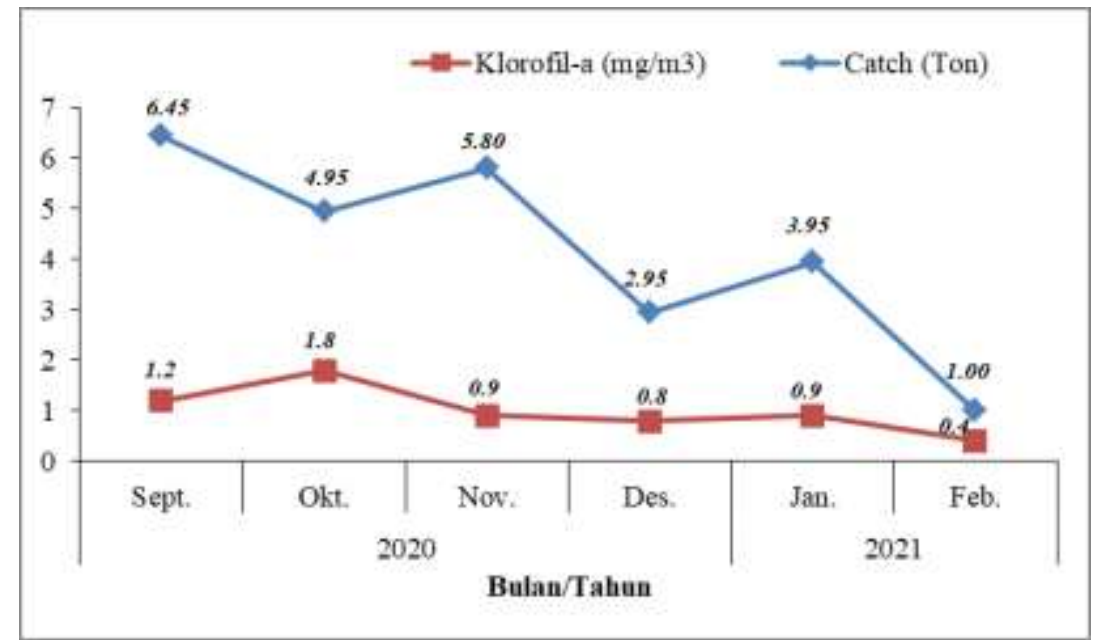

Gambar 9. Fluktuasi Rata-Rata Klorofil-a Bulanan dengan Hasil Tangkapan Ikan Pelagis Kecil di Perairan Teluk Weda.

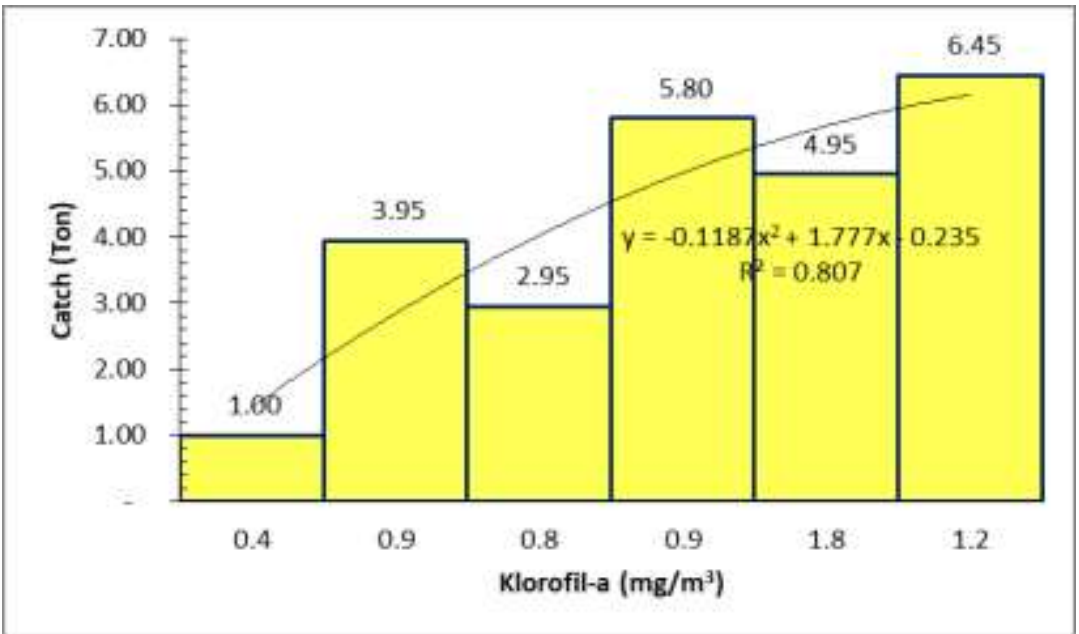

Gambar 10. Hubungan Klorofil-a dan Hasil Tangkapan Ikan Pelagis Kecil di Perairan Teluk Weda.

Hasil penelitian lain menunjukan adanya hubungan antara konsentrasi klorofil-a dengan hasil tangkapan ikan pelagis kecil, diantaranya hasil penelitian Adnan (2010) di perairan Kalimantan Timur, didapat bahwa konsentrasi klorofil-a cenderung mempengaruhi hasil tangkapan ikan pelagis kecil, dimana meningkatnya konsentrasi klorofil-a perairan diikuti dengan meningkatnya hasil tangkapan ikan pelagis kecil, hal yang sama didapat oleh Kuswanto, et al., (2017) di Perairan Teluk Lampung, dimana konsentrasi klorofil-a berpengaruh nyata terhadap hasil tangkapan ikan pelagis kecil (ikan tongkol) dengan nilai koefisien deteminasi sebesar 0.807 . 


\section{PENUTUP}

kondisi klorofil-a pada perairan teluk weda cukup fluktuatif pada bulan September 2020 sampai Februari 2021 dengan nilai rata-rata adalah $1.0 \mathrm{mg} / \mathrm{m}^{3}$, dan nilai terendah adalah $0.4 \mathrm{mg} / \mathrm{m}^{3}$ pada bulam Februari 2021 dan nilai tertinggi $1.8 \mathrm{mg} / \mathrm{m}^{3}$ pada bulan Oktober 2020. Jenis hasil tangkapan ikan pelagis kecil yang merupakan hasil tangkapan kapal KM. Fanzer 01 di perairan Teluk Weda adalah terdiri dari ikan layang (Decapterus sp), tongkol (Euthynnus affinis), kembung (Rastreliger $s p$ ), dan selar (Selaroides $s p$ ). Komuditas tangkapan utama yang didaratkan adalah ikan laying yang merupakan spesies dominan dengan persentase mencapai $80-90 \%$ dari total hasil tangkapan.

Saran penulis untuk penelitian selanjutnya yaitu perluh dilakukan penelitian lanjutan untuk mendapatkan data yang lebih banyak mengenahi pengaruh klorofil-a terhadap hasil tangkapan ikan pelagis kecil di setiap musim sehinggah menjadi bahan informasi bagi nelayan dalam melakukan proses penangkapan.

\section{DAFTAR PUSTAKA}

Akhlak, M. A., Supriharyono, \& Hartoko, A. (2015). Hubungan Variabel Suhu Permukaan Laut, Klorofila dan Hasil Tangkapan Kapal Purse Seine yang Didaratkan Di TPI Bajomulyo Juwana. Dipenogoro Journal of Maquares, 4(4), 128-135.

Ambardhy, J H, 2004. Physical and Chemical Properties Water. Pegangan Training Budidaya. PT. Central Bahari. Januari4. 200.

Apriyanto, Nunung. 2012. Seluk -Beluk Tunagrahita dan Strategi Pembelajarannya. Yogyakarta JAVALITERA.

Arief, M. Adawiah, S, W. Parwaty, E. Hamzah, R. Prayogo, R. 2015. Pengembangan Model Ekstraksi Suhu Permukaan LautMenggunakan Data Satelit Landsat 8, Studi Kasus: Teluk Lampung. Jurnal Penginderaan Jauh. Vol 12: (2): 107-122.

Azizah, A dan Wibisana, H. 2020. Analisa Temporal Sebaran Suhu Permukaan Laut Tahun 2018 Hingga 2020 Dengan Data Citra Terra Modis. Jurnal Kelautan. 13 (3): 196-205.

Bafagih, A., Hamzah, S., \& Tangke, U. (2017). Hubungan antara suhu permukaan laut dan hasil tangkapan ikan julung di Perairan Pulau Ternate Provinsi Maluku Utara. Prosiding Seminar Nasional KSP2K II, 23 1(2), https://ejournal.unkhair.ac.id/index.php/ksppk/article/view/631.

Tangke, Umar, John W. Ch. Karuwal, Achmar Malawwa, and Mukti Zainuddin. 2016. "Analisis Hubungan Suhu Permukaan Laut, Salinitas Dan Arus Dengan Hasil Tangkapan Ikan Tuna Di Perairan Bagian Barat Pulau Halmahera." Jurnal IPTEKS UNHAS 3(5): 363-82.

Akhlak, Miladiyah Ahsanul, Supriharyono, and Agus Hartoko. 2015. "Hubungan Variabel Suhu Permukaan Laut, Klorofil- A Dan Hasil Tangkapan Kapal Purse Seine Yang Didaratkan Di TPI Bajomulyo Juwana." Dipenogoro Journal of Maquares 4(4): 128-35.

Dinsa Kelautan dan Perikanan Kabupaten Haltim (Ed.). (2020). Statistik Perikanan Tangkap Kabupaten Halmahera Timur (1st ed.).

Hamuna, B., Paulangan, Y. P., Dimara, L. (2015). Kajian suhu permukaan laut mengunakan data satelit Aqua-MODIS di perairan Jayapura, Papua. Depik Jurnal Ilmu-Ilmu Perairan, Pesisir dan Perikanan. Vol 4 (3): 160-167.

https://oceancolor.gsfc.nasa.gov/l3/ dan https://tanahair.indonesia.go.id/.

Husein, Umar. 2011. Metode Penelitian Untuk Skripsi Dan Tesis Bisnis Edisi 11. Jakarta: PT. Bumi Aksar.

Karuwal, John. 2019. "Dinamika Parameter Oseanografi Terhadap Hasil Tangkapan Ikan Teri (Stolephorus Spp) Pada Bagan Perahu Di Teluk Dodinga, Kabupaten Halmahera Barat." Jurnal Sumberdaya Akuatik Indopasifik 3(2): 123-40.

Kasim, F. 2010. Analisis Distribusi Suhu Permukaan Menggunakan Data Citra Satelit Aqua-Modis dan Perangkat Lunak Seadas di Perairan Teluk Tomini. Jurnal Ilmiah Agropolitan, 3(1), 270 276.

Kuswanto, Tiara Dea, Mega Laksmini Syamsuddin, and Sunarto. 2017. "Hubungan Suhu Permukaan Laut Dan Klorofil-a Terhadap Hasil Tangkapan Ikan Tongkol Di Teluk Lampung." Jurnal Perikanan dan Kelautan VIII(2): 90-102.

Leavastu T. Hela I. 1970. Fisheries Oceanogra-phy and ecology. Londong : fishing news books ltd.

Limbong, M. 2008. Pengaruh Suhu Permukaan Laut Terhadap Jumlah Dan Ukuran Hasil Tangkapan 
Ikan Cakalang Di Perairan Teluk Pelabuhan Ratu Jawa Barat. Departemen Sumberdaya Perikanan. Fakultas Perikanan Dan Ilmu Kelautan, Institut Pertanian Bagor. Bogor.

Lillesand dan Kiefer, 1990. Penginderaan jauh dan Interperstasi Citra. (Ahli Bahasa oleh Dulbahri). Gajah Mada Unversitas Press. Yogyakarta.

Merta, IGS; S. Nurhakim dan J. Widodo, 1998. Sumberdaya Perikanan Pelagis Kecil. Dalam Potensi dan Penyebaran Sumberdaya Ikan Laut Di Perairan Indonesia. Komnas Pengkajian Stok Sumberdaya Ikan Laut, LIPI. Jakarta.

Mann, K.H and J.R.N. Lazier. 1996. dynamic of marine ecosystems: Biological physical interaction in the oceans.

Mardhatillah, N., Raharjo, M. F., \& Olivya, M. (2016). Sistem Informasi Zona Potensi Penangkapan Ikan Berbasis GIS di daerah Perairan Sulawesi. Prosiding Seminar Teknik Elektro \& Informaika, November, 31-48.

Nelwan A. 2016. kapasitas penangkapan kawasan ikan pelagis kecil di perairan pantai barat sulawesi selatan. fish scientiae, Volume 1 No. 2, Desember 2011, hal. 117-137.

Prahasta, Eddy. 2005. Konsep-Konsep Dasar Sistem Informasi Geografi. Bandung: Informatika.

Putra, E., Jonson Lumban Gaol, Vincentius P. Siregar. 2012. Hubungan Konsentrasi Klorofil-A dan Suhu Permukaan Laut dengan Hasil Tangkapan Ikan Pelagis Utama di Perairan Laut Jawa dari Citra Satelit Modis. Jurnal Teknologi Perikanan dan Kelautan. Vol. 3. (2): 1-10.

Putra, Ega, Jonson Lumban Gaol, and Vincentius P. Siregar. 2017. "Hubungan Konsentrasi Klorofil-a Dan Suhu Permukaan Laut Dengan Hasil Tangkapan Ikan Pelagis Utama Di Perairan Laut Jawa Dari Citra Satelit Modis." Jurnal Teknologi Perikanan dan Kelautan 3(2): 1-10.

Putra, I. N. J. T., Karang, I. W. G. A., Puta, I. D. N. N. 2019. Analisis Temporal Suhu Permukaan Laut di Perairan Indonesia Selama 32 Tahun (Era AVHRR). Journal of Marine and Aquatic Sciences. Vol 5(2): 234-246.

Sugiyono dan Agus, Susanto. 2015. cara mudah belajar SPSS dan Lisrel. CV. Alfabeta: Bandung.

Rahardjo, S. Harpasis, S.S. 1983. Oseanografi Perikanan 1. CV. Petra Djaja. Jakarta.

Valiela I. 1984. Marine Ecologycal Processes. New York: Springer-verlag.

Wicaksono, A., Muhsoni, F. F., Fahrudin, A. 2010. Aplikasi Data Citra Satelit NOAA-17 Untuk Mengukur Variasi Suhu Permukaan Laut Jawa. Jurnal Kelautan. Vol. 3(1): 70-74.

Wyban, J.A. dan Sweeney, J.N. 1991. Intensive Shrimp Produkction Technologi. The Oceanic Institute: Hawai. USA.

Yuniarti, A., Maslukah, L., Helmi, M. (2013). Studi Variabilitas Suhu Permukaan Laut Berdasarkan Citra Satelit Aqua MODIS Tahun 2007-2011 di Perairan Selat Bali. Jurnal Oseanografi, 2(4): 416421.

Adnan. 2010. "Analisis Suhu Permukaan Laut Dan Klorofil-A Data Inderaja Hubungannya Dengan Hasil Tangkapan Ikan Tongkol (Euthynnus Affinis) Di Perairan Kalimantan Timur." Jurnal Amanisal 1(1): 1-12.

Saing, Rizky Adolf A, Heron Surbakti, and Hartoni. 2018. "Identifikasi Daerah Penangkapan Ikan Pelagis Berdasarkan Suhu Permukaan Laut Dan Konsentrasi Klorofil - A Menggunakan Citra Modis Di Perairan Bangka Bagian Barat." Maspari Journal 10(january 2015): 1-8.

Simbolon, Domu, and Satriyanson Girsang. 2009. "Sebaran Fitoplankton Dewasa Ini Relatif Mudah." : 297-306.

Surya Gentha Akmal, Achmad Fahrudin, and Syamsul Bahri Agus. 2017. "Distribusi Spasial Kelimpahan Sumberdaya Ikan Di Perairan Selat Sunda." Jurnal Pengelolaan Perikanan Tropis 1(1): 2531.

Syofyan, Irwandy, Rommie Jhonerie, and Kasman AR. 2009. "Coastal Zone, Fishing Ground, GIS Technology, Malacca Strait, Overlay Index Model Method, Stow Net." Jurnal PERIKANAN dan KELAUTAN 14(2): 128-34.

Zulkhasyni. 2015. "Pengaruh Suhu Permukaan Laut Terhadap Hasil Tagkapan Ikan Cakalang Di Perairan Kota Bengkulu." Jurnal Agroqua 13(2): 68-73. 